Livestock Production and Land Use in Hills and Uplands

Occasional Publication No. 18 - British Society of Animal Production 1994

edited by T. L. J. Lawrence, D. S. Parker and P. Rowolinson

\title{
Genetic improvement of hill ewes
}

\author{
W. Haresign', B. G. Merrell ${ }^{2}$ and R. W. Richards ${ }^{3}$ \\ 'University of Nottingham, Faculty of Agricultural and Food Sciences, Sutton Bonington, Loughborough LE12 5RD \\ 'ADAS Redesdale, Otterburn, Newcastle upon Tyne NE19 1SB \\ ${ }^{3} A D A S$ Pwllpeiran, Cwmystwyth, Aberystwyth, Dyfed SY23 4AB
}

\section{Introduction}

There is a clear need to improve financial returns from hill sheep to help maintain rural populations in hill/upland areas while at the same time reducing the reliance of hill sheep farmers on social/ production type subsidies. Particular problems with hill sheep are their small carcass size and poor conformation, which result in reduced values for both draft ewes and wether lambs. These poor carcass attributes are also passed down to the lowland producer through the production of poor conformation halfbred ewes out of hill ewes. With the increasing pressures being placed on the lowland sector to improve carcass quality, many producers are beginning to look at the possibility of breeding their own replacement top-cross ewes. Any widespread adaption of this practice will further undermine the profitability of sheep production in the hill and upland sectors.

Evidence from flocks of hill ewes at ADAS Redesdale and ADAS Pwllpeiran has indicated variation both within and between breeds in the conformation of wether lambs slaughtered at a constant fat class. For example, 52\% Welsh Mountain and 54\% Scottish Blackface wethers produced carcasses which classified as $\mathrm{R}$ conformation or better, compared with only $7 \%$ Swaledale wethers. In addition, it is possible to identify a limited number of ewes of each breed which, over a number of successive lambings, have consistently produced wether lambs with good conformation and above average carcass weights. The existence of such variation suggests that, with appropriately designed genetic selection programmes, it should be possible to improve carcass quality of hill sheep to the benefit of all sectors of the industry.

\section{Material and methods}

A selected nucleus ( $\approx 60$ ewes) and an unselected control flock are to be established at ADAS Redesdale (Scottish Blackface ewes) and ADAS Pwllpeiran (Welsh Mountain ewes). Selection of ewes into the nucleus will be based on their ability consistently to produce lambs of good conformation and above average carcass weights. These will be selected from a base population of approximately 1600 Scottish Blackface and 1000 Welsh Mountain ewes. The nucleus flocks will remain 'open' for the first few years. Multiple ovulation and embryo transfer (MOET) will be used each year to increase the rates of genetic gain for carcass quality. Although this technique has been used by some lowland pedigree breeders in recent years, no attempt has yet been made to extend it to hill ewes maintained in harsh hill environments.

During the autumn of 1991 a pilot study was conducted to monitor the ovarian responses of hill ewes (43 Welsh Mountain ewes in mid October and 40 Scottish Blackface ewes in mid November) to a standard superovulatory treatment. Intravaginal progestagen sponges $\left(\right.$ Chronogest $^{\circledR}$, Intervet Laboratories Ltd, Cambridge) were inserted into all ewes (day 0) to synchronize the ewes. Eight twice daily injections $(1.25 \mathrm{ml})$ of a highly purified ovine FSH preparation (Ovagen ${ }^{\circledR}$, Immuno-Chemical Products Ltd, New Zealand) were given, spanning the period from 2.5 days before until 1 day after the removal of the sponge on day 12 . Ovulatory responses were determined by counting the numbers of corpora lutea present on day 20 using laparoscopy conducted under local anaesthesia.

\section{Results}

Only one Welsh Mountain ewe (ovulation rate of 0 ) and two Scottish Blackface ewes (ovulation rates of 0 and 1) failed to respond to treatment. However, in a further Scottish Blackface ewe there were 17 corpora albicantia present, suggesting that, although this animal had responded to treatment, the corpora lutea had regressed prematurely. The mean superovulatory responses for the two breeds (Welsh Mountain 10.35 (s.d. 3.54) per ewe treated; Scottish Blackface 12.65 (s.d. 5.68) per ewe treated) were similar to those obtained in lowland breeds (Haresign, 1990). 
The frequency distributions of ovulation rates for the two breeds are presented in Figure 1. As expected, there was a wide degree of variation in superovulatory response between ewes of both breeds. However, the reasons for the different patterns of distribution of ovulation rate between the two breeds are unclear.

Regression analysis indicated that there was no significant relationship between body condition score and ovulation rate for either breed.

\section{Discussion}

These results indicate that hill ewes are as responsive as lowland breeds to superovulatory treatment programmes. If the levels of fertilization, embryo recovery and survival of transferred embryos for hill ewes maintained in a hill environment prove to be similar to those obtained in lowland breeds, then these results suggest that it should be possible to achieve a mean annual ewe productivity of around five lambs per donor ewe treated. This would result in a marked increase in the annual rate of genetic improvement for carcass quality compared with that possible by natural mating.
The real responses to a fully fledged MOET programme in the two nucleus flocks will be determined in subsequent years. Future studies will also investigate the possible use of objective techniques such as computer analysis of photographic imaging to assess conformation in the live animal and thereby help identify the best animals produced within the nucleus flocks.

Once clear genetic differences between the nucleus and unselected control flocks have been established it will be important to monitor whether the superiority is passed down to lambs produced out of halfbred ewes and to model the relationships between carcass quality and survival traits to ensure that improvement of carcass quality does not compromise hardiness of either the breeding ewe or its neonatal lamb.

\section{References}

Haresign, W. 1990. Controlling reproduction in sheep. In New developments in sheep production (ed. C. F. R. Slade and T. L. J. Lawrence), Occasional publication, British Society of Animal Production no. 14, pp. 23-37.
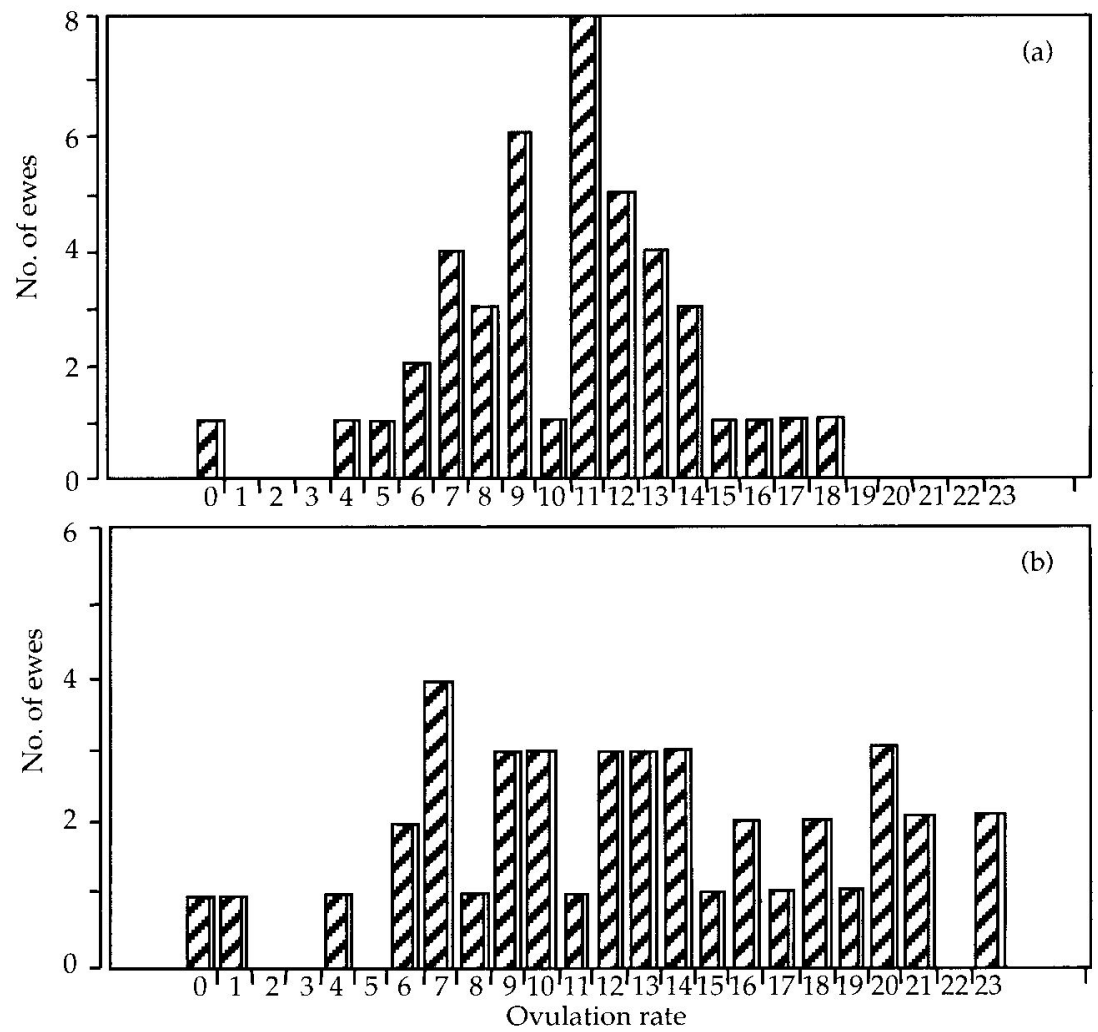

Figure 1 Frequency distribution of ovulation rate in (a) Welsh Mountain and (b) Scottish Blackface ewes to the induction of superovulation with Ovagen $\mathbb{B}$. 